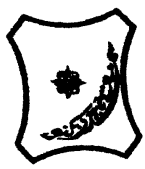

Bayero Journal of Pure and Applied Sciences, 9(1): 68 - 75

Received: January, 2016

Accepted: May, 2016

ISSN $2006-6996$

\title{
EFFECTS OF Senna occidentalis LEAF SUPPLEMENT ON BLOOD GLUCOSE LEVEL, LIVER ENZYMES AND TOTAL PROTEIN IN ALLOXAN-INDUCED DIABETIC WISTAR RATS
}

\author{
*Gidado, N.M., Tanko, Y., Sada, N.H. and Mohammed, A. \\ Department of Human Physiology, Ahmadu Bello University, Zaria, Nigeria. \\ * Correspondence author: yusuftanko@yahoo.com
}

\begin{abstract}
Diabetes mellitus is one of the most common non communicable diseases around the world and is responsible for many deaths resulting from some of its serious complications. Senna occidentalis Linn. is extensively being used in folklore medicine to cure and/or manage many disease conditions, although its adequate validation as therapeutic (specifically anti-diabetic and hepatoprotective) effects has not been established. The aim of this study is to determine the effects of Senna occidentalis leaf supplement on blood glucose level, liver enzymes and total protein in alloxan-induced diabetic wistar rats. Diabetes was induced by single intraperitoneal injection of alloxan (150 $\mathrm{mg} / \mathrm{kg})$. Thereafter the rats were fed with Senna occidentalis leaf supplement at doses of 12.5\%, 25\% and 50\% .Also Glibenclamide was used as a standard drug (2 $\mathrm{mg} / \mathrm{kg}$ ) as positive control and diabetic control received distilled water as negative control. Blood glucose levels were measured at day 0, 4, 8, 12 and 16. The liver enzymes and total protein were also determined using the serum and histopathological studies of the pancreas and liver were conducted. Quantitative phytochemical screening revealed that the supplement has high amount of phytoconstitutuents like total phenols, flavonoids, tannins, saponins and alkaloids, which have a percentage composition of 20\%, 10.80\%, 15\%, 0.55\% and $7.20 \%$, respectively. Blood glucose levels of all animals treated with the supplement were reduced significant/y $(p<0.05)$ by about $82.13 \%, 88.36$ and $81.78 \%$ respectively when compared with that of the untreated diabetic control group. There was also an increase in the total protein $(p<0.05)$ to $90.98 \pm 6.02,73.72 \pm$ 3.02 and $92.23 \pm 4.01$, respectively in comparison to that of the untreated diabetic group having $69.04 \pm 3.59 ;$ and hepatotoxicity due to the observed increase in the activities of all the liver enzymes as well as hepatocellular necrosis, sinusoidal congestion and hemorrhage as revealed in the histopathological studies of the liver. This study shows that S. occidentalis leaf supplement has potent hypoglycemic effect due to its high content of active principles that possess strong and potent insulinomimetic and $\beta$-cell regenerating potential as depicted by the histopathological studies of the pancreatic tissue, even though, some cytotoxic agents like the cytotoxic saponins may be present in the supplement which is capable of causing damage to both pancreas and liver. These findings prove its use in traditional medicine for the treatment of diabetes but with caution due to its probable potential to induce hepatotoxicity.

Keywords: Antidiabetic, Hepatoprotective, Hepatotoxicity, Phytoconstitutuents, Insulinomimetic,
\end{abstract} Senna occidentalis

\section{INTRODUCTION}

International Diabetes Federation (IDF) defined diabetes as a chronic metabolic disease characterized by elevated levels of blood glucose (or blood sugar) which over time leads to serious damage to the heart, blood vessels, eyes, kidneys and nerves (IDF, 2006).It is characterized by abnormally elevated levels of blood glucose due to complete or relative insufficiency in insulin secretion and /or insulin action together with chronic hyperglycemia (high fasting sugar level above $126 \mathrm{mg} / \mathrm{dl}$ ) as well as disturbances in carbohydrate, fat and protein metabolism (Patel and Sharma, 2014). International Diabetes Federation(IDF) and the World Health Organization (WHO) have reported that about 1.5 million deaths are directly attributed to diabetes each year predicting that it will be the seventh leading cause of death in 2030, the world over, and that about $9 \%$ of adults in the world have diabetes of which 90\% have type 2 diabetes (IDF, 2006; WHO, 2006). Furthermore, Suleiman et al. (2011) reported an estimated increase in diabetes cases of about $38.20 \%$ in 2007 when compared to 2002 incidence in Katsina state, Nigeria.

Senna occidentalis is a plant native more to Africa, Asia, and America, and both the leaves and the seeds are used in herbal medicine and belong to the family Fabaceae/Leguminosae. It is a low branching perennial shrub and grows to about three (3 ) cm feet high (Sadiq et al., 2012). Senna has compound leaves with narrow linear-to-oval-shaped dark green leaflets. In the spring and summer it has yellow pea-like flowers which are followed by brown pods which contain brown seeds. Leaves, fruit and flowers of senna are used for medicinal purpose (Malviya and Sharma, 2013). 
The leaves of $S$. occidentalis Linn were revealed by Adeyemoet al. (2014) to contains protein; carbohydrate; fiber; lipids; vitamins; moisture; caloric value and low levels of toxic agents whose levels could be reduced on processing before consumption, and therefore concluded that, the plant can contribute significantly to the nutrient requirements of man and may ameliorate some nutrition related illnesses. In a review by Heme and Latina (2012) the aqueousethanolic extract of Senna occidentalis (L.) leaves was said to produce significant hepatoprotective and Antidiabetic activities. Onakpa andAjagbonna (2012) in their study concluded that the results of their study $(p<0.01)$ indicated the presence of active diabetes principles in senna occidentalis leaves extract, which seems to confirm its folkloric uses as an Antidiabetic agent. Verma et al. (2011) reported that aqueous extract of s.Occidentalis exhibited significant antidiabetic activity in alloxan-induced diabetic wistar rats by regeneration of pancreatic $\beta$-cells and therefore can be used for diabetic treatment. Raniet al. (2010) reported thatchrysophanol and the methanolic extracts of the leaves of senna occidentalis were able to reduce elevated levels of Aspartate transaminase, Alanine transaminases and alkaline phosphate in Paracetamol - induced hepatotoxicity. This work was designed to evaluate the effects of Senna occidentalis leaf supplement on blood glucose levels, liver enzymes and total protein in alloxaninduced diabetic wistar rats.

\section{MATERIALS AND METHODS \\ Plant Collection and Authentication}

Senna occidentalis was obtained from Funtua town of Funtua Local Government, Katsina State. The plant was identified and authenticated at the Herbarium Unit, Department of Biological Sciences, Ahmadu Bello University, Zaria and a voucher number (661) was given and deposited for future reference.

\section{Experimental Animals}

Thirty adult male wistar rats weighing $100 \mathrm{~g}$ to $150 \mathrm{~g}$ were obtained from the Department of Human Physiology, Faculty of Medicine, Ahmadu Bello University, Zaria, Nigeria. The animals were housed under standard conditions having free access to feed and water ad libitum.

\section{Equipment and Chemicals}

Distilled Water, One-Touch Digital Glucometer, Digital Weighing Machine, Cages, Syringes ( $5 \mathrm{mls}, 2 \mathrm{mls}$ and $1 \mathrm{ml})$, Spatula, Set of Dissecting Kit, Normal Saline, Formal Saline, Containers, Pins, Alloxan Monohydrate (purchased from Sigma Chemical Company St. Louis USA).

\section{Diet Formulation}

The leaves of this plant were shade-dried at room temperature. The dried leaves were then milled into powder (using mortar and pestle). The powder was combined in different proportions of $12.50 \%, 25 \%$ and $50 \%$ to the standard animal diet, and the diet was fed to the diabetic animals for 16 days.

\section{Induction of Diabetes Mellitus}

The experimental animals (those to be induced with diabetes mellitus and oxidative stress) were intraperitoneally injected with $150 \mathrm{mg} / \mathrm{kg}$ of alloxan monohydrate to produce experimental hyperglycemia.After about 72 hours of alloxan injection, animals with fasting blood glucose levels of $180 \mathrm{mg} / \mathrm{dL}$ and above were considered diabetic(Mohan et al., 2011).

\section{Experimental Design}

The experimental animals were grouped into six groups at random, with each group having five animals $(n=5)$.Group 1:Normoglycemic rats received normal diet and Normal Saline $10 \mathrm{ml} / \mathrm{kg}$, Group 2:Diabetic untreated control rats that received normal diet and Normal Saline $10 \mathrm{ml} / \mathrm{kg}$, Group 3: Diabetic Positive Control rats that received normal diet and Glibenclamide $2 \mathrm{mg} / \mathrm{kg}$, Group 4:Diabetic rats that received diet containing $12.50 \%$ Senna occidentalis leaf powder, Group 5:Diabetic rats that received diet containing 25\% Senna occidentalis leaf powder, Group 6: Diabetic rats that received diet containing $50 \%$ Senna Occidentalis leaf powder.

\section{Determination of Blood glucose Level}

Determination of blood glucose level was conducted by collecting blood samples from the animal tail vein on a four day interval (starting with day 0 then 4, 8, 12 and 16) for a period of 16 days. A digital OneTouch glucometer was used to monitor blood glucose levels throughout the experiment.

\section{Blood Collection and Tissue Isolation}

At the end of 16 days treatment period, the animals were fasted overnight and sacrificed using chloroform as an anesthetic agent. Blood samples were collected via cardiac puncture using $5 \mathrm{ml}$ syringes and the serum was used for biochemical assays. The pancreas and the liver tissues of the experimental animals were harvested and fixed in $10 \%$ formol-saline solution, and were used for histopathological studies.

\section{Quantitative Phytochemical Screening}

Preparation of Fat Free Sample: Sample ( $2 \mathrm{~g}$ )was weighed and defatted with $100 \mathrm{~mL}$ of diethyl ether using a soxhlet apparatus for 2 hours. The quantity of each of the following phytochemical was estimated using standard procedure: alkaloids(Harborne, 1998), flavonoids (Bohm and Kocipai- Abiazan, 1994), tannins(Van-Burden and Robinson, 1981)total phenol (spectrophotometric method) and saponins( Obadoni and Ochuko, 2001)

\section{Assessment of Liver Enzymes}

The activities of serum Aspartate Aminotransferase (AST), Alanine Aminotransferase (ALT) and that of Alkaline Phosphatase(ALP) wereassayedusing colorimetric assay kits (Randox, Northern Ireland) according to manufacturer's instruction and values were expressed in IU/L.

\section{Determination of Serum Total Proteins}

Serum total protein were estimated as outlined by Burkhardt and Batsakis (1978). 


\section{Histopathological Studies}

The harvested pancreas and liver tissues were processed in an automatic tissue processor and sections of $5 \mu$ thick were made using leitz base sledge microtome and processed routinely by embedding in paraffin (Gurring, 1992). The sections obtained were stained in haematoxylin for 5 minutes and thereafter were placed in eosin for 1 minute. After the staining process, the sections were then washed with tap water, air dried, cleared using xylene and mounted under a light microscope (Cullings, 1993).

\section{Statistical Analysis}

Data collected were expressed as mean \pm SEM and analyzed using one way analysis of variance, ANOVA, and Tukey's post-hoc test was used to compare the level of significance between the control and treatment groups, using SPSS version 20.0. Values of $p<0.05$ were considered significant.

\section{RESULTS}

Phytochemical screening: The result of the phytochemical screening (Table 1 ) revealed the high concentration of total phenols, tannins and flavonoids, a moderate amount of alkaloids, and a very low amount of saponins.

Effect of the Leaf Supplement on Blood Sugar Level (BSL): Blood glucose levels of all animals treated with the supplement were seen to reduce significantly $(p<0.05)$ by about $82.13 \%, 88.36 \%$ and $81.78 \%$ respectively when compared with that of the untreated diabetic control group(Table 2).

Effect of the Leaf Supplement on Liver Enzymes and Total Protein: Table 3 shows that there is an increase in the total proteins in the groups fed with 12.5 and $50 \%$ supplements of Senna occidentalis ( $p<$ $0.05)$ to $90.98 \pm 6.02,73.72 \pm 3.02$ and $92.23 \pm$ 4.01 , respectively in comparison to that of the untreated diabetic group having $69.04 \pm 3.59$; and slight hepatotoxicity due to the observed increase in the activities of all the liver enzymes.

Table 1: Phytochemical constituentsof Senna occidentalis leaf supplement.

\begin{tabular}{ll}
\hline Phytoconstituents & Percentage Composition \\
\hline Alkaloid & $07.20 \%$ \\
Saponins & $00.55 \%$ \\
Tannins & $15.00 \%$ \\
Flavonoids & $10.80 \%$ \\
Total Phenol & $20.00 \%$ \\
\hline
\end{tabular}

Table 2: Effect of Senna occidentalis leaf supplement on blood glucose level $(\mathrm{mg} / \mathrm{dL})$ in rats

\begin{tabular}{llllll}
\hline Expt'I Group & BGL Day 0 & BGL Day 4 & \multicolumn{1}{c}{ BGL Day 8 } & BGL Day 12 & BGL Day 16 \\
\hline NGR (NC) & \multirow{2}{*}{$68.00 \pm 6.25$} & $50.40 \pm 2.75$ & $70.60 \pm$ & $63.09 \pm 3.87$ & $70.40 \pm 3.54$ \\
& & $414.60 \pm$ & $326.40 \pm$ & $324.20 \pm$ & $292.40 \pm$ \\
DR (DC) + NS & $430.60 \pm 56.14$ & 80.37 & 31.04 & 23.06 & 25.13 \\
$10 \mathrm{ml} / \mathrm{kg}$ & & $456.80 \pm$ & $315.20 \pm$ & $253.00 \pm$ & $128.80 \pm$ \\
DR (PC) + GBC 2 & $434.60 \pm 53.22$ & 88.31 & 58.20 & 70.79 & 34.50 \\
$\mathrm{mg} / \mathrm{kg}$ & & $352.20 \pm$ & $300.20 \pm$ & $133.20 \pm$ & $79.60 \pm$ \\
DR + 12.5 \% SOLS & $436.20 \pm 52.64$ & 46.37 & 77.40 & $51.11^{*}$ & $13.01^{*}$ \\
& & $386.00 \pm$ & $231.20 \pm$ & $81.80 \pm$ & $50.60 \pm$ \\
DR + 25 \% SOLS & $434.60 \pm 60.19$ & 95.34 & 45.52 & $13.38^{*}$ & $13.01^{*}$ \\
& & $302.60 \pm$ & $210.40 \pm$ & $75.60 \pm 7.05^{*}$ & $79.20 \pm$ \\
DR + 50 \% SOLS & \multirow{2}{*}{$434.80 \pm 70.83$} & 122.83 & 46.52 & $5.27 *$
\end{tabular}

NGR (NC):Normoglycemic Rats (Negative Control); DR (DC):Diabetic Rats (Diabetic Control) + Normal Saline; DR (PC): Diabetic Rats (Positive Control) + Glibenclamide2mg/kg; SOLS:Senna occidentalis Leaf Supplement;BGL: Blood Glucose Level.

*Statistically Significant at $\mathrm{p}<0.05$ when compared with Untreated Diabetic Control

Table 3:Effect of Senna occidentalis leaf supplement on liver enzymes (IU/L) and total protein $(\mathrm{mg} / \mathrm{ml})$ in rats

\begin{tabular}{llrll}
\hline Experimental Group & \multicolumn{1}{l}{ AST } & \multicolumn{1}{c}{ ALT } & \multicolumn{1}{l}{ ALP } & Total Protein \\
\hline NGR (NC) & $255.40 \pm 17.83$ & $59.64 \pm 10.21$ & $277.20 \pm 48.97$ & $93.16 \pm 3.11$ \\
DR (DC) + NS 10ml/kg & $345.80 \pm 40.15$ & $117.70 \pm 23.82$ & $218.00 \pm 37.53$ & $69.04 \pm 3.59$ \\
DR (PC) + GBC 2 mg/kg & $244.00 \pm 53.48$ & $110.56 \pm 32.06$ & $54.40 \pm 5.54$ & $77.81 \pm 3.73$ \\
DR + 12.5 \% SOLS & $438.40 \pm 37.78$ & $80.58 \pm 20.04$ & $608.60 \pm 243.37$ & $90.98 \pm 6.02 *$ \\
DR + 25 \% SOLS & $444.00 \pm 26.74$ & $146.74 \pm 31.43$ & $932.20 \pm 200.69 *$ & $73.72 \pm 3.02$ \\
DR + 50 \% SOLS & $366.00 \pm 68.53$ & $121.88 \pm 35.85$ & $752.40 \pm 155.78$ & $92.23 \pm 4.01 *$ \\
\hline
\end{tabular}

NGR (NC): Normoglycemic Rats (Negative Control); DR (DC): Diabetic Rats (Diabetic Control) + Normal Saline; DR (PC): Diabetic Rats (Positive Control) + Glibenclamide $2 \mathrm{mg} / \mathrm{kg}$; SOLS: Senna occidentalis Leaf Supplement; AST: Aspartate aminotransferase; ALT: Alanine aminotransferase; ALP: Alkaline Phosphatase.

*Statistically Significant at $\mathrm{p}<0.05$ when compared with Untreated Diabetic Control 


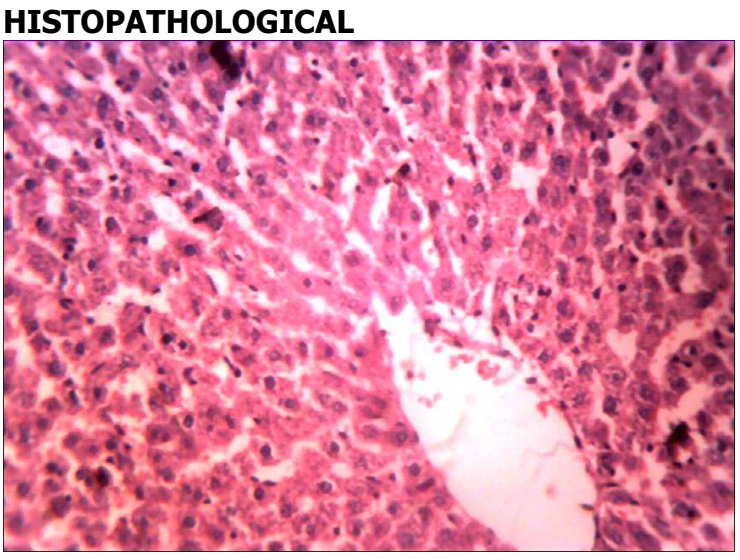

Ia

Plate Ia: Photomicrograph of a section of liver from normoglycaemic wistar rats administered with $2 \mathrm{ml}$ of normal saline for sixteen days using $\mathrm{H}$ and $\mathrm{E}$ stain; and a magnification of $\times 250$. This shows normal hepatocytes. Plate Ib: photomicrograph of a section of pancreas from normoglycaemic wistar rats administered with $2 \mathrm{ml}$ of normal saline for sixteen days using $\mathrm{H}$ and $\mathrm{E}$ stain; and a magnification of $\times 250$. This shows normal islet cells

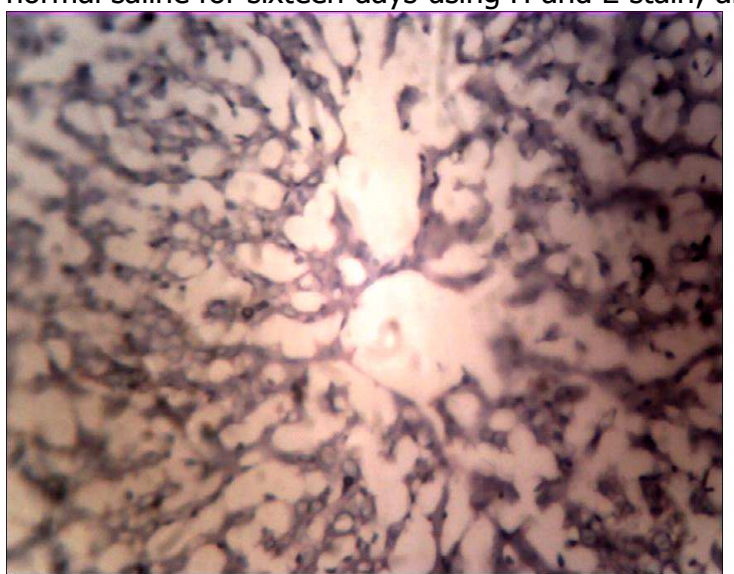

IIa

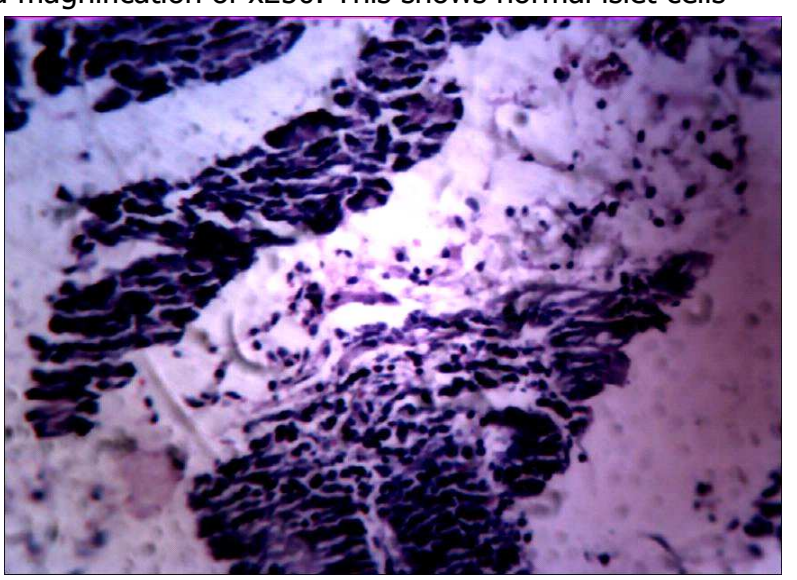

IIb

Plate IIa: Photomicrograph of a section of liver from untreated diabetic wistar rat administered with 2 mlof normal saline for sixteen days using $\mathrm{H}$ and $\mathrm{E}$ stain; and a magnification of $\mathrm{x} 250$. This result shows intense hepatocellular necrosis.

Plate IIb: Photomicrograph of a section of pancreas from untreated diabetic wistar rat administered with $2 \mathrm{ml}$ of normal saline for sixteen days using $\mathrm{H}$ and $\mathrm{E}$ stain; and a magnification of $\mathrm{x} 250$. This result shows intense islet necrosis.

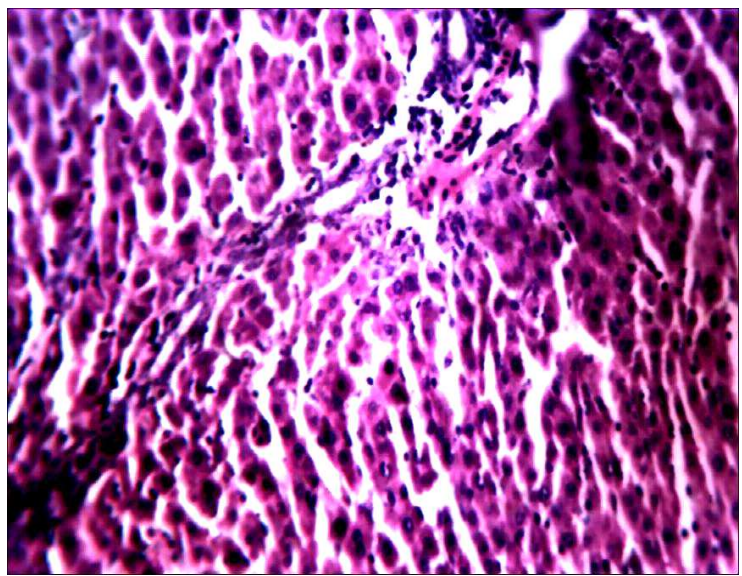

IIIb

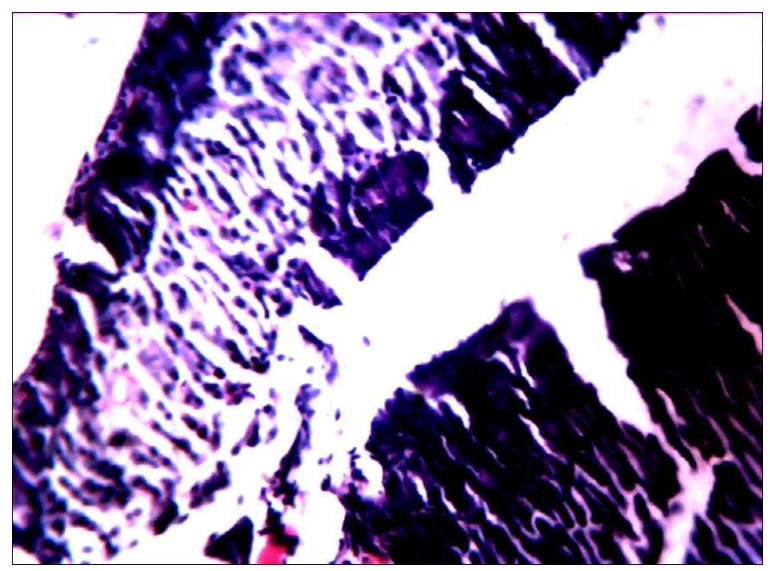

IIIa

Plate IIIa: Photomicrograph of a section of liver from diabetic wistar rats treated with $2 \mathrm{mg} / \mathrm{kgglibenclamide} \mathrm{for}$ sixteen days using $\mathrm{H}$ and $\mathrm{E}$ stain; and a magnification of $\mathrm{x} 250$. This shows slight hepatocellular necrosis.

Plate IIIb: Photomicrograph of a section of pancreas from diabetic wistar rats treated with2 $\mathrm{mg} / \mathrm{kgglibenclamide}$ for sixteen days using $\mathrm{H}$ and $\mathrm{E}$ stain; and a magnification of $\mathrm{x} 250$. This shows intense necrosis of islet cells. 
Bajopas Volume 9 Number 1 June, 2016
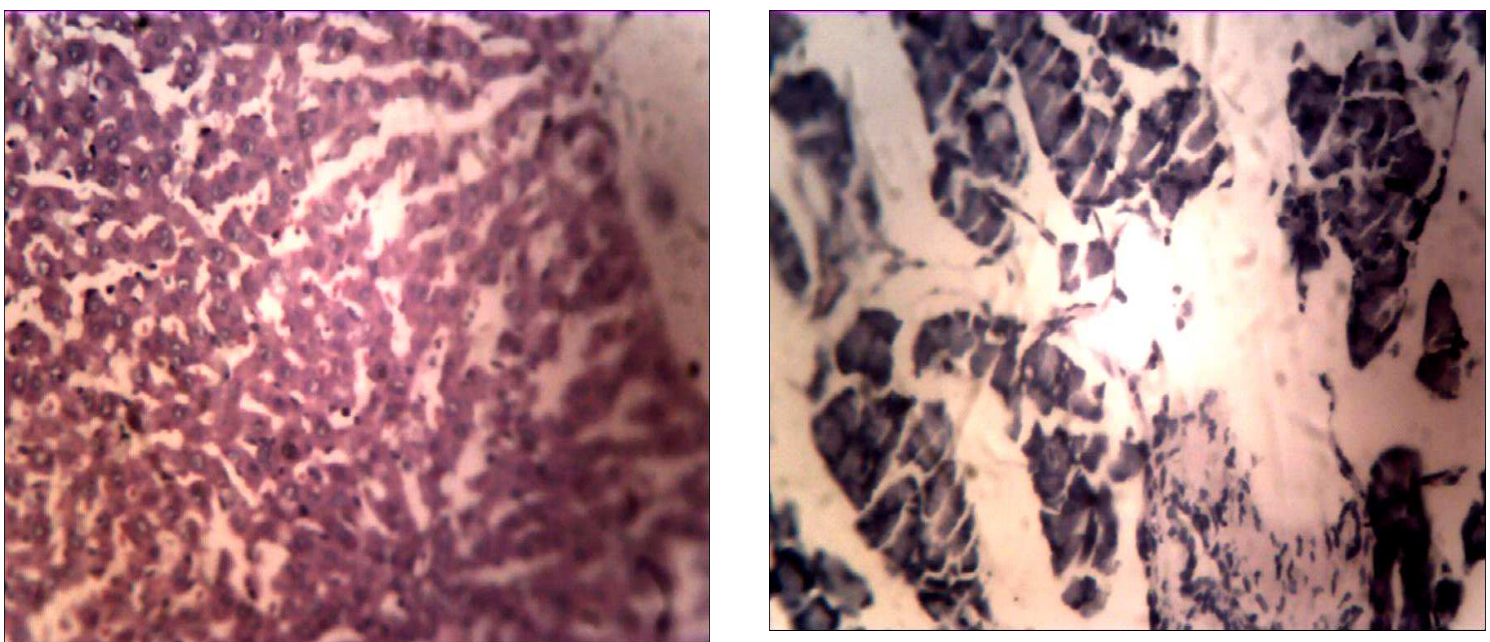

IVa

IVb

Plate IVa: Photomicrograph of a section of liver from diabetic wistar rats treated with $12.5 \%$ senna occidentalis leaf supplement for sixteen days using $\mathrm{H}$ and $\mathrm{E}$ stain; and a magnification of $\mathrm{x} 250$. It shows slight hepatocellular necrosis.

Plate IVb: Photomicrograph of a section of pancreas from diabetic wistar rats treated with $12.5 \%$ senna occidentalis leaf supplement for sixteen days using $\mathrm{H}$ and $\mathrm{E}$ stain; and a magnification of $\mathrm{x} 250$. It shows moderate regeneration of islet cells.

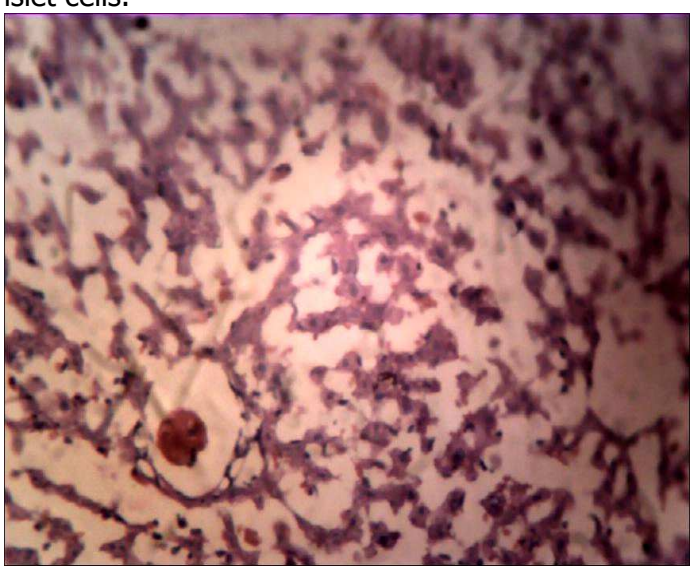

Va

Plate Va: Photomicrograph of a section of liver from diabetic wistar rats treated with $25 \%$ senna occidentalis leaf supplement for sixteen days using $\mathrm{H}$ and $\mathrm{E}$ stain; and a magnification of $\times 250$. It shows moderate hepatocellular necrosis with sinusoidal congestion.

Plate Vb: Photomicrograph of a section of pancreas from diabetic wistar rats treated with $25 \%$ senna occidentalis leaf supplement for sixteen days using $\mathrm{H}$ and $\mathrm{E}$ stain; and a magnification of $\times 250$. It shows moderate necrosis of islet cells.
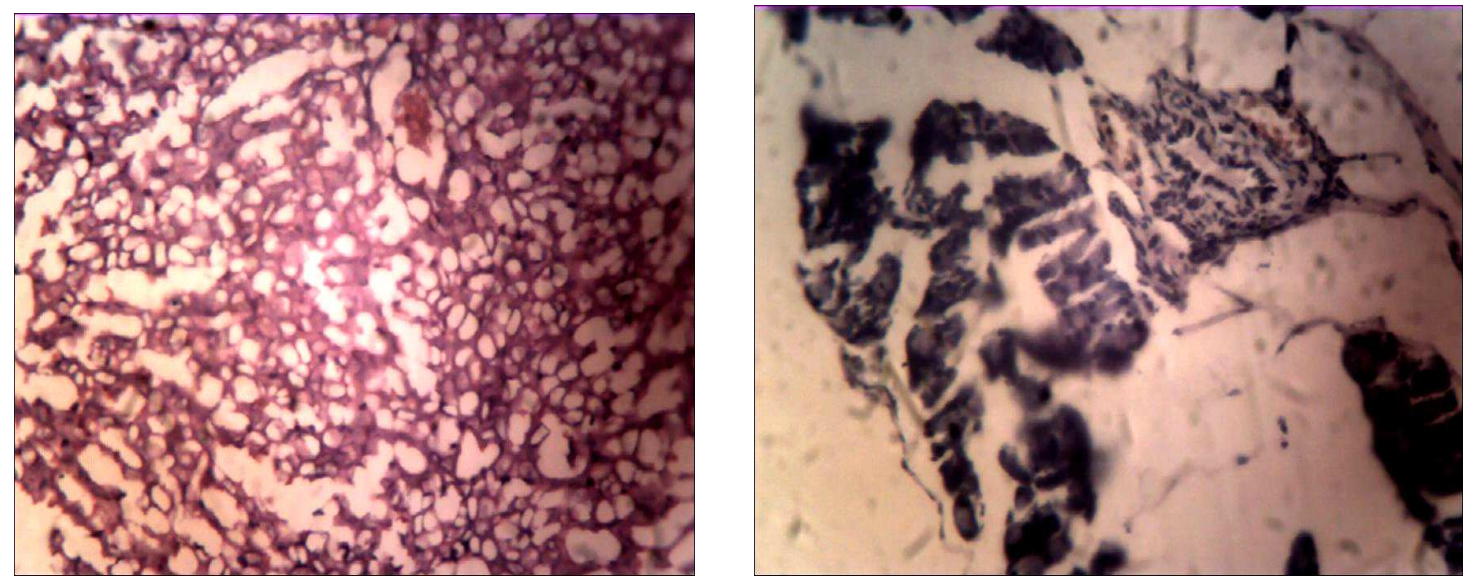

Plate VIa: Photomicrograph of a section of liver from diabetic wistar rats treated with $50 \%$ senna occidentalis leaf supplement for sixteen days using $\mathrm{H}$ and $\mathrm{E}$ stain; and a magnification of $\times 250$. It shows moderate hepatocellular necrosis.

Plate VIb: Photomicrograph of a section of pancreas from diabetic wistar rats treated with $50 \%$ senna occidentalis leaf supplement for sixteen days using $\mathrm{H}$ and $\mathrm{E}$ stain; and a magnification of $\mathrm{x} 250$. It shows moderate regeneration of islet cells 


\section{DISCUSSION}

Diabetes mellitus is a metabolic disease associated with impaired glucose metabolism which in effect alters intermediary metabolism of lipids and proteins adversely (Onakpa and Ajagbonna, 2012). Alloxan, a beta cytotoxin, destroys pancreatic $\beta$-cells of islets of Langerhans resulting in a decrease in endogenous insulin secretion and paves ways for the decreased utilization of glucose by body tissues leading to elevation of blood glucose level, decreased protein content, increased levels of cholesterol and triglycerides(Lenzen, 2010). This study was conducted to study the effects of Senna occidentalis leaf supplement on some biochemical profiles and oxidative stress biomarkers of alloxan-induced diabetic wistar rats. This involves the study of its antihyperglycemic and antioxidant activities in wistar rats as well as to provide an introductory approach for the evaluation of its traditional preparation in order to scientifically validate the therapeutic potential of the leaves of this plant used as supplement in the control of diabetes. In this study, it was observed that alloxan induced diabetic rats that were treated with $S$. occidentalis leaf supplement at doses of $12.5 \%, 25 \%$ and $50 \%$ to their feed daily for sixteen days produced significant fasting blood glucose lowering activity in Day 12 and Day 16 dose dependently when compared with the untreated diabetic control, The potency of this effect was seen to be more when compared to that of Glibenclamide as a standard drug. This result is found to be in agreement with that of Garba et al.(2015), who reported that various dose levels of the methanolic extracts of Senna occidentalis was able to reduce the blood glucose significantly $(p<0.05)$ but however, not dose-dependently. Furthermore, this is in accordance with work of Emmanuel et al. (2011), Verma et al.(2011) and Singh et al.(2011) who reported that the aqueous extracts of the leaves of $S$. occidentalis in male albino Wistar rats has shown a significant hypoglycemic activity. Emmanuel et al.(2011) also reported that methanolic extract of leaves exhibited significant reduction in fasting blood glucose levels that was found to be dose dependent. This is also in accordance with the work of Singh et al.(2011) who reported that butanol extract of the leaves of Senna occidentalis in mice had shown significant antidiabetic activity. The hypoglycemic activity observed could be due to the high phytonutrients content that have been found to be essential in the management of diabetes due to their insulinomimetic, insulin secretogogue, $\beta$ cell regenerating and strong antioxidant potentials.

The untreated diabetic rats had decreased levels of serum total proteins when compared with the normal negative control rats. Sixteen days supplementation with $S$. occidentalis leaf supplement increased the serum level of total protein significantly $(p<0.05)$. Alloxan induced diabetes leads to elevated levels of liver marker enzymes such as AST, ALT and ALP when compared with normal control rats. Following sixteen days treatment with Senna occidentalis leaf supplement, ALT and ALP serum levels were further elevated even beyond that of the untreated diabetic control although not dose dependently but significantly in the case of ALP when compared with the untreated diabetic control. Thus, animals treated with Senna occidentalis leaf supplement can be said to have developed some hepatic damages which was evident from the increase in the enzyme activities as well as histopathological studies of the liver from the Senna occidentalis leaf supplement treated groups which shows hepatocellular necrosis with sinusoidal congestion and hemorrhage. But the observed increase in serum total protein level in the Senna occidentalis leaf supplement treated groups after sixteen days when compared with the diabetic untreated groups depicts that the severity of the damage to the liver tissue is not much microscopically based on the results obtained, sixteen days supplementation with Senna occidentalis leaf supplement may be toxic. This result is not in agreement with the work of Rani et al. (2010) who reported that chrysophanol and methanolic extract of leaves of Senna occidentalis were able to reduce elevated levels of AST, ALT and alkaline phosphatase when tested in male Albino Wistar rats against PCM induced hepatotoxicity.

It is also not in accordance with the work of Sastry et al.(2011) who reported that the aqueous extract of $S$. occidentalis seeds administered at doses of 100,200 and $400 \mathrm{mg} / \mathrm{kg}$ body weight orally to rats in paracetamol (PCM) - induced hepatotoxicity decreased Paracetamol- induced injuries in rat liver in a dose - dependent manner. But it is however in agreement with the work carried out by Nuhu and Aliyu (2008) who reported that aqueous leaf extract of senna occidentalis (Linn.) has hypoproteinaemic effect that it significantly $(P<0.05)$ increased $A L T$, AST and ALP serum levels, and finally concluded that the crude extract of $S$. occidentalis leaves may be slightly toxic as a concoction for liver ailments.

Investigation on the phytochemical compounds of $S$. occidentalis leaf aqueous extract revealed the presence of tannins, phenols, glycosides, cardiac glycosides, triterpene, steroids, carbohydrates, saponins and flavonoids but indicate the absence of anthraquinones. This is quiet in agreement with the results ofMehta et al.(2010), Taiwo et al. (2013) and Odeja (2014) who worked on various extracts of the leaves of this plant and finally reported the presence of anthraquinones among other active principles. Furthermore, quantitative phytochemical assay of the most important phytoconstitutuents revealed that Senna occidentalis leaf supplement has high quantity of phenols, tannins, flavonoids and alkaloids with saponins as the least in terms of quantity. These phytochemicals are known to be biologically active and thus are thus are responsible for many defence activities of the plant. Phytochemicals exert most of these activities via different mechanisms; tannins for instance act by iron deprivation, hydrogen bonding or specific interactions with vital proteins such as enzymes that bring about its roles as stable and potent antioxidants. 
Flavonoid is another phytochemical found in the leaf of $S$. occidentalis, flavonoids exhibit a wide range of biological activities the most important of which is its potent antioxidant and antidiabetic properties like myricetin which is a polyhydroxylated flavonol has been demonstrated to possess insulinomimetic properties, stimulate lipogenesis and transport glucose in the adipocytes, hence lowering blood glucose; and that flavonoids can regenerate the damaged beta cells in the alloxan induced diabetic rats and acts as insulin secretogogue as reported by Geetha (1994). This highlights many of its health promoting functions in organisms, which are important for prevention of diseases associated with oxidative damage of membrane, proteins and DNA, and further supports the usefulness of $S$. occidentalis in folklore remedies and one of the reasons why this plant is widely used for the treatment of many diseases among many tribes in Africa as reported by Hodek et al.(2002) and Tasdemir et al.(2006). Saponin which is also one of the constituents of $S$. occidentalis is responsible for numerous pharmacological properties. They are considered a key ingredient in traditional Chinese medicine and are responsible for most of the observed biological effects as it is also known to produce inhibitory effects on inflammation as reported by Just et al. (1998) and Liu and Henkel(2002). They are also known to reduce the uptake of certain nutrients including glucose and cholesterol at the gut through intraluminal physicochemical reaction hence, it has been reported to have hypocholesterolemic effect and thus its presence in $S$. occidentalis may support its use as an agent for lessening metabolic burden that would have been placed in the liver as reported byMohanet al.(2011). Tannins such as epigallo-catechin-3-gallate, which is one of the phytochemical component of $S$. occidentalis, has been found to exhibits hypoglycemic activity as reviewed by Verma et al.(2011). Total phenolic content is very important in plants because of their ability to trap free radicals directly or scavenges them through a series of coupled reactions with antioxidant enzymes due to their hydroxyl

\section{REFERENCES}

Abeer, E.E. and Amr, A.R. (2013). Hypoglycemic effect of hazelnut and its effect on some sexhormones in alloxan induced diabetic in female rats. Pakistan Journal of Nutrition, 12(3), 229-238.

Adeyemo, D.J., Gimba, C.E., Gwarzo, U.S. and Paul, E.D. (2014). Nutritional and anti-nutritional analyses of senna occidentalis Linn. Retrievedfromhttp://scholarsresearchlibrary. Com /archive.html

Bohm BA, Kocipai- Abyazan R (1994). Flavonoid and condensed tannins from the leaves of Vaccinum raticulation and Vaccinum calcyimium. Pacific Sci., 48: 458-463.

Burkhardt, R.T. and Batsakis, J.C. (1978). An interlaboratory comparison of serum total protein analysis. American Journal of Clinical Pathology, 70, 508-510.

Cullings, C.F.A. (1993). Handbook of Histological Techniques, $6^{\text {th }}$ edition. Butterworths, London.

Dolui, A., Das, S. and Kharat, A. (2012). Antihyperglyceamic effect of Cassia sophera leaf groups, and thus its presence in $S$. occidentalis endowed it with strong antioxidants potential as reported by Mehta et al.(2010). And it has been proved by the literature that there is a positive linear correlation between the total phenolic concentration and the antioxidant capacity some medicinal plants particularly $S$. occidentalis as reported by Verma, et al.(2011). Furthermore, several authors like OliverBever (1986) and Rhemann and Zaman(1989) have reported that flavonoids, steroids/terpenoids, phenolic acids are known to be bioactive antidiabetic principles. These observations enumerated on the properties of phytochemicals found in $S$. occidentalis assert its usefulness in traditional medicines and its relevance on folklore medicine in the prevention, treatment and management of infectious and oxidative stress related diseases such as diabetes mellitus and its complication.

\section{CONCLUSION}

The results of this study indicates that Senna occidentalis leaf supplement possess significant antidiabetic activity, hyperproteinaemic effects and increase in ALT, AST and ALP coupled with the histopathological examinations of the liver tissue were indications that the Senna occidentalis leaf supplement may possess both hepatoprotective and cytotoxic effects.

\section{Authors' contributions}

This work was carried out in collaboration between all authors. Authors NMG and YT designed the study, wrote the protocol, and wrote the first draft of the manuscript. Author NHS managed the literature searches, analyses of the study performed the spectroscopy analysis. Author AM managed the experimental process. All authors read and approved the final manuscript

\section{Conflict of Interests}

Authors have declared that no conflict of interests exist.

extracts in rats with alloxan induced diabetes. Asian Journal of Traditional Medicine, 71 ), 8-13.

Emmanuel, S., Rani, M.S. and Sreekanth, M.R. (2011). Antidiabetic activity of Cassia occidentalis Linn. instreptozotocin-induced diabetic rats: a dose dependent study. International Journal of Pharmacy and Biomedical Sciences 1(4): B14 B25.

Garba, R., Saidu, A.N., Adeyemi, H.R.Y. and Muhammad, H.L. (2015). Effect of methanolic extract of cassia occidentalis $\mathrm{L}$. root bark on body weight and selected biochemical parameters in alloxan induced diabetic rats. British Journal of Pharmacology and Toxicology, 6(2), 39-49.

Geetha, B.S., Mathew, B.C. and Augusti, K.T. (1994). Hypoglycemic effects of leucodelphinidin derivative isolated from Ficus bengalensis Linn. Indian Journal of Physiological Pharmacology, 38, $220-222$.

Gurring, E. (1992). Staining animal tissues: Practical and Theoretical. Leonard Hill, London. 
Harborne, J.B. (1998). Phytochemical Methods - A Guide to Modern Techiques of Plant Analysis. Chapman and Hall, London. pp. 60-66.

Hodek, P., Trefil, P. andStiborova, M. (2002). Flavonoids - potential and versatile, biologically active compounds interacting with cytochrome P450. Chem. Biol. Int., 139(1), 1-21.

Just, M.J., Recio, M.C., Giner, R.M., Cueller, M.J., Manez, S., Bilia, A.R. and Rios, J.L. (1998). Antiinflammatory activity of unusual lupine saponins from Bupleurium fruitcescens. PlantaMedica 64, 404-407.

Lenzen, S. (2010). Alloxan and streptozotocin diabetes. Advance Research Institutes of Diabetes Animals, 6(4), 113-122.

Liu, J. and Henkel, T. (2002). Traditional Chinese medicine (TCM): Are polyphenols and saponins the key ingredients triggering biological activities? Curr. Med. Chem., 9, 1483-1485.

Malviya, R. and Sharma, R. (2013). Kasamarda (Senna occidentalis Linn): Ayurvedic approach. Journal of Pharmaceutical and Scientific Innovation. Jaipur, Rajasthan, India. Retrieved from www.jpsionline.com

Mehta, S., Kamboj, P., Faujdar, S., Sawale, J. and Kalia, A.N. (2010). In-vitro antioxidant activity of cassia occidentalis seeds. Pharmacologyonline,3, 217224.

Mohan, V.R., Kalpana, D.V., Maruthupandian, A., Shanmugasundaram, R. and Tresina, S.P. (2011). Antidiabetic, Antihyperlipidaemic and antioxidant activity of senna auriculata (L.) Roxb. leaves in alloxan-induced diabetic rats. International Journal of Pharm Tech Research, 3(2), 747-756.

Nuhu, A.A. and Aliyu, R. (2008). Effects of cassia occidentalis aqueous leaf extract on biochemical markers of tissue damage in rats. Tropical Journal of Pharmaceutical Research, 74), 1137-1142.

Odeja, O.O., Obi, G., Ogwuche, C.E., Elemike, E.E. andOderinlo, O.O. (2014). Phytochemical screening, antioxidant and antimicrobial activities of senna occidentalis (L.) leaves. International Journal of Herbal Medicine, 2(4), 26-30. Retrieved from www.florajournal.com

Oliver-Bever, B. (1986). Medicinal Plants in Tropical West Africa. Cambridge University Press, London. Pp.: $245-267$

Obadoni BO, Ochuko PO (2001). Phytochemical studies and comparative efficacy of the crude extract of some homeostatic plants in Edo and Delta states of Nigeria. Global J. Pure Appl. Sci., 8: 203-208.

Onakpa, M.M.and Ajagbonna, O.P. (2012).Antidiabetic potentials of Cassia occidentalis leaf extract on alloxan induced diabetic albino mice. International Journal of PharmTech Research, 4(4), 1766-1769.

Patel, V. and Sharma, V. (2014). The role of natural antioxidants in oxidative stress induced diabetes mellitus. Research Journal of Pharmaceutical Science, 3(4), 1-6.

Rani, M.S., Emmanuel, S., Sreekant, M.R. andIgnacimuthu, S. (2010). Evaluation of in vivo antioxidant and Hepatoprotective activity of cassia occidentalisLinn.Againstparacetamol-induced liver toxicity in rat. International Journal of Pharmacy and Pharmaceutical Sciences,2(3), 67-70.

Rhemann, A.V. and Zaman, K. (1989). Medicinal plants with hypoglycemic activity. Journal of Ethnopharmacology, 26, 1- 55 .
Sadiq, I.S., Shuaibu, M., Bello, A.B., Tureta, S.G., Isah, A., Izuagie, T., Nasiru, S. and Kamaru, M.B. (2012). Phytochemistry and Antimicrobial Activities of Cassia Occidentalis Used for Herbal Remedies. Journal of Chemical Engineering 1(1).

Sadiq, S.I., Shuaibu, M., Bello, A.B., Tureta, S.G., Isah, A., Izuagie, T., ... Kamaru, M.B. (2012). Phytochemistry and antimicrobial activities of cassia occidentalis used for herbal remedies. Journal of Chemical Engineering, 1(1), 38-40.

Sastry, A.V.S., Sastry, V.G., Appalanaidu, B., Srinivas, K. and Annapurna, A. (2011). Chemical and pharmacological evaluation of aqueous extract of seeds of Cassia occidentalis. Journal of Chemical and Pharmaceutical Research, 3(2), 566-575.

Singh, K. and Verma, B. (2013). Role of Ayurvedic herbs on madhumeha (diabetes mellitus). International Journal of Ayurvedic and Herbal Medicine, 3(2), 1136:1140.

Singh, P.S., Salwan, C, and Mann, A.S. (2011). Evaluation of antidiabetic activity of leaves of cassia occidentalis.International Journal of Research in Pharmacy andChemistry, 1(4), 904913.

Suleiman, M., Abdulkarim, B. and Ahmed, A. (2011). Incidence of diabetes mellitus at the federal medical center Katsina, Katsina State, Nigeria: a retrospective study. Bayero Journal of Pure and Applied Sciences, 4(2), $100-102$.

Taiwo, F.O., Akinpelu, D.A., Aiyegoro, O.A., Olabiyi, S. and Adegboye, M.F. (2013). The biocidal and phytochemical properties of leaf extract of cassia occidentalis Linn. African Journal of Microbiology Research, 727), 3435-3441. DOI: 10.5897/AJMR2013.5673.

Tasdemir, D., Kaiser, M., Brun, R., Yardley, V., Schmidt, T.J., Tosun, F. and Reudi, P. (2006). Antitripanosomal and anti leishmanial activities of flavonoids and their analogues, In: Vitro, structure - activity relationship and quantitative studies. Antimicrobial Agents and Chemotherapy, 50(4), 1352-1364.

Trease, G. and Evans, S.M. (2002). Pharmacognosy. (15 ${ }^{\text {th }}$ Edition). English Language Book Society, BailliereTindall, London.Pp 23-67.

Van-Burden TP, Robinson T (1981). The biochemistry of alkaloids, 2nd edition. Springer, Heidelberg, Newyork.

Vashishtha, V.M., John, T.J. and Kumar, A. (2009).Clinical and pathological features of acute toxicity due to Cassiaoccidentalis in vertebrates. Indian Journal of Medical Research 130, 23-30.

Verma, L., Khatri, A., Kaushik, B., Patil, U.K. and Pawar, R.S. (2011). Antidiabetic activity of cassia occidentalislinn. in normal and alloxan-induced diabetic rats. IndianJournal of Pharmacology, 42, 224-228.

World Health Organization (2006) Definition and Diagnosis of Diabetes Mellitus and Intermediate Hyperglycemia: Report of a WHO/IDF Consultation, 21-22. 